\title{
Vegetables, Herbs and Spices: The Importance of Family and Tasting
}

\author{
Pamela A. Heinrichs1,2, Cassandra J. Nikolaus1, Brenna Ellison1, \\ Sharon M. Nickols-Richardson ${ }^{1}$, Karen Chapman-Novakofski ${ }^{1}$ \\ ${ }^{1}$ University of Illinois at Urbana-Champaign, Champaign, IL, USA \\ ${ }^{2}$ Currently Address: The Hersey Company, Hershey, PA, USA \\ Email: kmc@illinois.edu
}

How to cite this paper: Heinrichs, P.A., Nikolaus, C.J., Ellison, B., Nickols-Richardson, S.M. and Chapman-Novakofski, K. (2016) Vegetables, Herbs and Spices: The Importance of Family and Tasting. Health, 8, 1554-1565.

http://dx.doi.org/10.4236/health.2016.814153

Received: October 26, 2016

Accepted: November 20, 2016

Published: November 23, 2016

Copyright $\odot 2016$ by authors and Scientific Research Publishing Inc. This work is licensed under the Creative Commons Attribution International License (CC BY 4.0).

http://creativecommons.org/licenses/by/4.0/

\section{c) (i) Open Access}

\begin{abstract}
Objective: To explore why and how consumers utilize vegetables, herbs and spices. Methods: Focus groups were conducted with adult participants $(\mathrm{n}=54)$ to determine attitudes, self-efficacy, and behaviors related to liking and usage of vegetables, herbs and spices as well as strategies to increase vegetable intake. Results: Seasonal availability, and family-centered memories and practices were motivation for vegetable intake. A diverse number of vegetables $(n=39)$ were listed as favorites based on taste and versatility, but seasonings were not commonly included in responses regarding preparation. Participants felt that vegetable dish names should reflect ingredients explicitly; that seasonings enhanced vegetable flavors; and that salt and pepper were most commonly used seasonings. The preferred strategy to increase vegetable consumption was through tasting or sampling opportunities; seasoning use was not mentioned. However, participants perceived that suggestions or demonstrations on how to prepare vegetables at home would be helpful. Personal gardens were mentioned frequently, but were not connected to strategies for increasing intake. Conclusions and Implications: Vegetable intake has a family focus that should be emphasized to increase intake. Efforts to increase intake could emphasize flavor and versatile preparation methods through tasting opportunities or educational demonstrations.
\end{abstract}

\section{Keywords}

Dietary Habits, Focus Groups, Vegetables, Spices, Herbs

\section{Introduction}

Vegetable intake recommendations are largely unmet in the United States (US). Only 
$10 \%$ to $30 \%$ of US adults meet the recommended intake of two to three and a half cups of vegetables per day [1]. The average intake is one and one half cups per day, according to the National Health and Nutrition Examination Survey, 2009-2010 database ( $\mathrm{n}=$ 9042 adults) [2]. In a nationally representative sample of 373,580 adults, $9 \%$ reported meeting vegetable recommendations [3].

Explorations into factors related to greater vegetable intake have evaluated various behavioral theories and how theoretical constructs relate to behavior. Choice architecture has been applied in a buffet-line intervention, where re-arranging the display successfully increased the quantity of salad vegetables selected by patrons [4]. When applying Stages of Change theory [5] to vegetable intake, self-efficacy best predicted stage movement [6] and moderated intake [7] [8]. Within the Theory of Planned Behavior [9], affective attitude and perceived behavioral control were significant predictors of intention to consume five vegetables and fruits per day, with intentions significantly linked to behavior [10].

One area that has not received much attention is use of herbs and spices with vegetables as a method of increasing intake. A sample of parents reported adding flavoring to just over half of vegetable preparations; however, spices were less frequently used than salt, butter or oil [11]. Interest in frequency of spice use was previously alluded to in analyses of over 2000 vegetable recipes from 36 countries that found vegetable dishes included spices less frequently than meat dishes. The most frequently included spices in vegetable dishes were black pepper, followed by onion, garlic and chili pepper [12].

While herbs and spices continue to be investigated for health benefits [13] [14] [15], the practical application of enhancing flavor and increasing vegetable intake has been less well studied. Previous sensory studies found that herb and spice use increased preference for reduced-fat meals and reduced-sodium tomato soup [16] [17]. Only one published intervention protocol that used herbs with vegetables was identified [18], but the focus was on impacting bone resorption, leaving a gap in knowledge regarding the ability of herbs and spices to facilitate vegetable intake. Therefore, the aim of the current study was to explore why and how consumers utilize vegetables, herbs and spices through qualitative focus groups.

\section{Methods}

Adults, aged 18 years or older, were recruited through a university social media website. Recruits had to have eaten carrots, broccoli, cauliflower, peas, squash, zucchini, Brussel sprouts, corn, potatoes, okra, or tomatoes at least once in the previous two months to be considered for the study. There were no other exclusion criteria. Sex, age and residence questions were asked during screening to stratify participants across focus groups as needed. Invitations to participate were sent by email, asking for availability. Four to eight participants were assigned to each conference call focus group time. Participants were called simultaneously by the moderator. Participants selected fictitious names to preserve confidentiality. Focus groups lasted an average of 38 minutes, after which participants were compensated with a $\$ 70$ gift card. 


\subsection{Focus Group Script}

The research team developed focus group questions, according to guidelines by Krueger and Casey [19], to learn about participants' vegetable-related perceptions and behaviors. Questions reflected affective attitudes, perceived behavioral control, and self- efficacy, as well as environmental influences (Table 1). Herbs and spices were not operationally defined for participants to encourage open and unrestricted focus group discussions. Seven experts in nutrition education were invited to review the focus group script. Six professors of nutrition or nutrition-related disciplines returned comments, and the script was refined. Flow and clarity were tested with investigator-led practice sessions.

Procedures for telephone focus groups were followed, including limiting the number of questions, keeping the focus group discussion to one hour or less, and calling on par-

Table 1. Focus group questions for why and how consumers utilize vegetables, herbs and spices.

\begin{tabular}{|c|c|}
\hline Theory Variable & Focus Group Questions \\
\hline \multirow[t]{3}{*}{ Attitudes } & $\begin{array}{l}\text { Would you tell me about the } 3 \text { vegetables you like the most? } \\
\text { Things like why you like them, how often you eat them, } \\
\text { how you like them prepared, or what meal you eat them? }\end{array}$ \\
\hline & $\begin{array}{l}\text { Next, I'd like your opinion on names: recipe names, vegetable products } \\
\text { you may buy (like a frozen package), or vegetable dish names on a menu. } \\
\text { There are generally } 4 \text { types of names: ones that describe the cooking method, } \\
\text { like "roasted", ones that describe the ingredients, like "rosemary", } \\
\text { ones that describe the general taste, like "spicey", and ones that create an image } \\
\text { or suggest ingredients or taste, such as southwestern or Italian. Are any of these } \\
\text { names more compelling for you to choose a vegetable than others, } \\
\text { and why or why not? Or in other words, What types of names do you } \\
\text { think would be most effective at getting people to select vegetables? Why? }\end{array}$ \\
\hline & $\begin{array}{l}\text { Next, I'd like to get your opinions on spices and herbs, particularly } \\
\text { in regards to vegetables. For instance, do they make vegetables more, } \\
\text { less or the same degree of appealing as a plain steamed or roasted vegetable? } \\
\text { If there are combinations of vegetables and seasonings } \\
\text { that come to mind or certain spices or herbs, please bring those up as well. }\end{array}$ \\
\hline \multirow[t]{2}{*}{$\begin{array}{l}\text { Environment } \\
\text { and behavioral } \\
\text { control }\end{array}$} & $\begin{array}{l}\text { Now I'd like you to take a moment and think about the } \\
\text { meal or meals you usually eat vegetables during. Could you tell me } \\
\text { about that meal? Things like, where the meal is, who is there if anyone, } \\
\text { who prepared it, and also why a vegetable is part of that meal? }\end{array}$ \\
\hline & $\begin{array}{l}\text { Now, I want to talk about eating in restaurants or cafeterias. } \\
\text { Could you tell me about yourself in terms of eating in restaurants, in general, } \\
\text { like how often and what types of restaurants, and then about vegetables ordered } \\
\text { or eaten in restaurants. Could you also discuss whether the vegetables } \\
\text { you eat in restaurants are the same as those you eat at home. }\end{array}$ \\
\hline Self-efficacy & $\begin{array}{l}\text { I want to talk a little about your cooking style. For instance, } \\
\text { do you like to try new recipes, do you need convenience? } \\
\text { Talk in general, but then specifically about how you prepare vegetables, please. }\end{array}$ \\
\hline $\begin{array}{l}\text { Behavioral } \\
\text { motivation }\end{array}$ & $\begin{array}{l}\text { Finally, I'd like your thoughts on how to motivate people to choose } \\
\text { more vegetables. Think as if you were selling vegetables } \\
\text { in a grocery store or if you had a restaurant or cafeteria. }\end{array}$ \\
\hline
\end{tabular}


ticipants who were not actively engaged [19]. All procedures were approved by the University of Illinois Institutional Review Board.

\subsection{Data Analysis}

Focus group conference calls were digitally recorded, and hand-written notes were taken. Recordings were transcribed verbatim. Two researchers met to review and agree on content analysis procedures [20] and inductive content development [21]. After 13 focus groups, transcriptions were evaluated independently by two researchers for codes, using content analysis. Researchers then met to discuss and agree on codes, and subsequently reviewed transcripts independently for themes. After meeting to discuss and reach agreement on themes, researchers independently reviewed the transcripts' saturation and outlying or emotionally presented responses. Concurrence was reached on these negative cases [22] for the final results as well as for saturation [23].

\section{Results}

One-hundred forty-six people responded to recruitment efforts. Among them, $11 \mathrm{did}$ not agree to participate before being screened, $34 \mathrm{did}$ not respond to the invitation to schedule a focus group and six declined to participate after completing screening. After 13 focus groups with 54 participants, saturation of responses was achieved; thus, the remaining screened participants $(n=41)$ were not scheduled. Focus group sizes ranged from two to six participants. Smaller groups were not planned, but some scheduled participants did not answer when called or had to leave for an emergency. Participants were mostly female $(n=46)$, with only eight males included (Table 2$)$. Four participants described themselves as vegetarians.

When asked to name their three favorite vegetables, 39 different vegetables were mentioned with broccoli, peppers (green or red) and asparagus with the highest frequencies. Participants primarily cited flavor as the reason for picking their favorite ve-

Table 2. Demographics of participants.

\begin{tabular}{cc}
\hline Demographic & Participants (n) \\
\hline Gender & 8 \\
Males & 46 \\
Females & \\
Age & 26 \\
18- to 39-years & 26 \\
40- to 59-years & 2 \\
over 60 years & \\
Residence & 35 \\
Illinois, USA & 19 \\
Other states & \\
\hline
\end{tabular}


getable $(n=28)$, followed by versatility of a vegetable's use $(n=15)$. Most participants ate vegetables at home $(n=33)$, with family $(n=28)$ or as part of the evening meal $(n=$ 41).

The majority $(\mathrm{n}=37)$ prepared household meals themselves or with a family member. Most participants reported eating vegetables when at restaurants $(n=31)$, though eating in restaurants was an infrequent activity. However, a frequent comment was that restaurants did not have many vegetable options available.

Roasting was the most popular vegetable preparation method $(n=31)$, followed by steaming $(n=21)$ and sautéing $(n=20)$. Although many believed spices and herbs could enhance vegetables $(n=24)$, when asked about the herbs and spices they use with vegetables, salt and pepper was the predominant response $(\mathrm{n}=19)$ "...most of my vegetables I do think I go simply with salt and pepper." A number of themes emerged from the focus groups and were categorized into two main ideas: motivations for eating vegetables (attitudes) and strategies to increase vegetable consumption (self-efficacy and behavioral control).

\subsection{Motivations for Eating Vegetables}

Family was the predominant thematic reason for eating vegetables. Health was identified as the main reason for consuming vegetables, both their own health as well as the health of their parents and children.

So for me it was more the way that I was raised and Mom now is... in a nursing home but Dad is still there so two or three times a week I'll go down and normally I'll make dinner and he'll do dishes. It's kind of a good trade off... And worrying about him eating enough vegetables and those kinds of things, I will always open up a jar of green beans or a jar of beets or something.

Children emerged as a motivator for serving vegetables at meals. Many stated their upbringing led them to believe that vegetables were a necessary part of the family's evening meal. Parents wanted to establish nutritious foods as part of their children's lives and form good dietary habits.

... if my children are there ... I feel it's always important to have that vegetable.

Um, and I as well try to offer two vegetables. That was done when I was a child and I still try to do it with my own kids.

Children were also important in deciding which vegetables to serve to the family. Many participants shared examples where their children determined which vegetables were served based on which ones they enjoyed eating. This illustrates how much participants value vegetable consumption as a part of their children's diets and lives.

Zucchini because my ... younger daughter who's 15 months now really enjoys it

... I have a 3 year old and that's what he'll eat

Seasonality was another strong motivator of vegetable consumption. Many participants had gardens at home, so harvest dictated which vegetables were consumed. Seasonality was mentioned regarding favorite vegetables, vegetable intake frequency, cooking methods and whether vegetables consumed at restaurants were the same as at home. 
... And we got a big garden so it's pretty much seasonal what vegetables we have um, so this time of year it's a lot of salads um in the wintertime a lot of soup.

Additionally, some noted they used herbs because they were grown in their garden at home.

I use a lot of parsley, chives, and dill with my vegetables. Mainly because I grow it in my back yard.

Even those who did not garden mentioned they liked to eat vegetables that were in season. Seasonality was used in conjunction with freshness.

Actually my husband and I eat a lot of seasonal vegetables so we have our favorites for every season. Now that I'm shopping the farmer's market is open in my village I'm able to get fresh asparagus. We use it for all three meals.

... we use asparagus because it's just so delicious it makes you think of spring and I think we pretty much eat if it four times a week in the spring when it's fresh because it's just so good and so yummy.

\subsection{Strategies to Increase Vegetable Consumption}

The primary strategy suggested to increase vegetable consumption was to present new ideas or items to consumers. Ideas included sampling or tasting opportunities, providing use and meal pairing suggestions and presenting new preparation techniques. Participants noted that in-store tastings introduced them to now-favorite vegetables of which they were previously intimidated or unaware. Participants also commented that learning about the vegetable and how it could be used in family meals had helped make some vegetables more accessible.

... we were not a parsnip family until ... [named grocery store] had a parsnip sample thing and now we eat parsnips because they're really good.

Like, if I'm at the farmer's market and it's something that I'm not familiar with if they have samples and examples of how I can use this or how I can incorporate this um, that would help a lot.

Several participants shared stories about discovering they liked a vegetable when they tried it prepared in a novel way. They suggested trying new cooking methods would be a good strategy to increase vegetable consumption.

... she didn't like vegetables at all most of her life and then someone told her to try them roasted and she can't get enough and so she eats a lot of roasted vegetables and she's lost a lot of weight ...

When participants were asked which of a list of dish names would make a vegetable dish most appealing in a store or restaurant, the majority of participants preferred names describing the cooking method and ingredients used. Participants repeatedly explained that they liked to know what they were getting in a vegetable dish. Names that were less specific and instead tried to illustrate a general genre of taste, such as Italian, were less preferable.

It also gives you an expectation of what it will taste like. So yes, I think any and all of those descriptive names are good. 
Respondents reported herbs and spices can add flavor to a vegetable dish, but no one mentioned using herbs and spices to increase vegetable consumption. However, many participants discussed eating vegetables in ethnic dishes, both at home and at restaurants, which typically use herbs and spices. Notably, Mexican $(\mathrm{n}=15)$ and Asian $(\mathrm{n}=$ 14) dishes were popular choices.

... I tend to think a lot about ethnicities, you know, in terms of variety um, so say broccoli could be in an Asian stir fry or in Mexican fajitas, um, you know things like that just to [indecipherable] out how flavors have the different ingredients and foods go together along with the spices and flavors based on kind of more traditional cuisines.

Um, we also really like Thai food so, and there's a lot of like bamboo shoots or eggplant that I don't generally cook at home but I really like them in the Thai cooking or Indian food.

\section{Discussion}

Food behavior is complex, with personal, interpersonal, and environmental factors influencing choice. In regards to vegetables, little is known except when vegetables and fruits are grouped together. For instance, a systematic review found that taste, availability, social influences, habits, marketing, time, and concerns about health may be factors influencing an individual's decision to consume fruits and vegetables [24]. However, choice about fruit may be quite different than choice concerning vegetables. For instance, the high cost of fruit is a perceived barrier, whereas poor appetite for vegetables was the reason for limited intake in a study of older adults [25].

While national surveys have reported that potatoes and tomatoes are the most frequently eaten vegetable by US adults [2], little has been published about adults' reported favorite or most frequently eaten vegetable beyond these results. Published reports instead focus on the associations of total fruit and vegetable intake and chronic disease prevalence [26], relationship to body weight [27], or individual vegetables and chronic disease prevalence [28].

Broccoli, peppers (green or red) and asparagus were mentioned most often in this study as favorite vegetable. Although the script was pilot-tested and feedback obtained from an expert panel, there may have been ambiguity in using the term "favorite" without clarification as to frequency. With 39 vegetables recounted by participants as a favorite, it was not clear how often these favorites were consumed. This is a limitation of the study. Some were clearly a "special occasion" vegetable or a treat. Indeed, one participant said

You asked about favorite vegetables and It's not necessarily the ones we eat most of ten. I love artichokes... It's not really a normal everyday food.

Although this project includes no data to support this conclusion, national intake data support the idea that broccoli may be both a favorite and frequently eaten vegetable. Broccoli intake in the US has increased for both fresh and frozen from approximately 8.1 pounds/person in 2000 to 9.2 pounds/person in 2015. In comparison, intake of green beans was 6.4, carrots was 10.4 pounds/person and intake of asparagus was 1.7 
pounds/person in 2015 [29]. However, it should be noted that the focus groups described in this study were conducted in the spring, when asparagus was in season, and many were gardeners themselves.

Reasons for increased frequency of intake included the versatility of the vegetable as well as the seasonality. Holmes and Gates [28] reported that seasonality was mentioned in regards to vegetable intake in interviews with older men and women, although not as often as was mentioned in regards to fruit. Neither of the reasons reported in these focus groups were previously included in the top twenty promoters of vegetable intake for urban, low income adults in 2008 [30].

Reports of eating at home more often than eating out was not a new finding, and the belief that vegetable options in restaurants are minimal has been reported by others [31]. Roasting and steaming vegetables were the most preferred preparation methods. Among six preparation methods for green beans and carrots, steamed was most preferred by children and young adults, although roasting was not a preparation method offered [32].

The concept of how participants were raised and how they want to raise their children were reasons for eating vegetables. These concepts have been reported by others, including Holmes and Gates [30] in a qualitative study with older men. Yeh et al. [33] also reported both childhood experiences with vegetables and desiring healthy meals for their current families among both older and younger focus group participants. The importance of family was also reported in a study investigating interventions to increase fruit and vegetable intake at the workplace or workplace plus home, concluding that the workplace plus home was more effective [34]. In addition, past experiences when eating vegetables may not need to be in a person's distance past in order to influence their vegetable eating habits. In a study of college students, Robinson, Blissett, and Higgs [35] found that the students recalled pleasant vegetable eating experiences and that this was related to higher vegetable liking and choice of larger vegetable portions. Therefore, connecting pleasant vegetable intake memories and current home practices may be valuable to increase intake.

Expectations of benefits on health have also been reported by others [31] [33]. However, providing more information about the health benefits of vegetables was mentioned by only a minority of focus group participants. Yeh et al. [33] noted that while most of their participants cited the health benefits of vegetables, and fruits, they also admitted they do not follow the guidelines for intake. Therefore, knowing the health benefits may not be a powerful motivator for improved intake.

The grocery store was the suggested place to learn about vegetables by participants advocating taste testing as a way to increase vegetable intake. In a study of child care providers, grocery stores were identified as the primary place they learned about vegetables (and fruits) and this information was then conveyed to the children [36]. None of the strategies for increasing vegetable and fruit intake outlined by the Center for Disease Control and Prevention (CDC) [37] were offered by participants as suggested strategies. This may be because the CDC's strategies had a broader viewpoint, but sug- 
gestions concerning access, cost and quality were not issues with which participants identified. However, although not suggested as a strategy, participants' home gardens clearly play a role in their personal vegetable intake and are part of the CDC's guidelines. Indeed, home gardens have been found to include a wide diversity of vegetables and can provide meaningful quantities of vegetables for home use [38].

Although participants reported growing herbs in addition to vegetables, reported combinations were mostly limited to tomatoes and basil. Indeed, most reported salt and pepper as the seasoning usually used in vegetable preparation, similar to the reported recipe analysis [12]. A lack of familiarity with vegetable seasoning could be overcome by tasting and recipe demonstrations.

While past research has explored strategies such as serving more of a vegetable [39], serving a wider variety of vegetables [40] and offering a vegetable subsidy (price reduction) to make them more affordable [41] to increase vegetable intake, focus group findings here suggest that tasting or sampling opportunities as well as preparation suggestions and demonstrations may be effective means to introduce consumers to new vegetables. Additional research is needed to better explain the interaction of favorite vegetables and frequently eaten vegetables.

Although the use of herbs and spices was not explicitly listed by focus group participants as a strategy to increase vegetable consumption, herbs and spices could likely be incorporated in tasting or sampling demonstrations. In such demonstrations, it is important to use a descriptive and informative name for the vegetable. Focus groups revealed that consumers prefer descriptive, yet straightforward, names that explain what they are eating and how the food was prepared. For instance, a name like "Roasted zucchini with chili powder and lime" would be preferred to "Southwestern-style zucchini". Insights from this research can be used to tailor recipes and can be built into educational programs and campaigns designed to increase vegetable intake.

\section{Acknowledgements}

This research was supported by an unrestricted gift from the McCormick Science Institute. The funding agency had no role in the design of the study, collection or analysis of data, interpretation of results, or decision to submit the manuscript for publication.

\section{References}

[1] U.S. Department of Health and Human Services and U.S. Department of Agriculture. (2015) 2015-2020 Dietary Guidelines for Americans. 8th Edition. http://health.gov/dietaryguidelines/2015

[2] Bowman, S.A., Clemens, J.C., Friday, J.E., Thoerig, R.C. and Moshfegh, A.J. (2014) Food Patterns Equivalents Intakes from Food: Mean Amounts Consumer per Individual. What We Eat in America, NHANES 2011-12. http://www.ars.usda.gov/Services/docs.htm?docid=23871

[3] Moore, L.V. and Thompson, F.E. (2015) Adults Meeting Fruit and Vegetable Intake Recommendations-United States, 2013. Morbidity and Mortality Weekly Report, 64, 709-713.

[4] Kongsbak, I., Skov, L.R., Nielsen, B.K., Ahlmann, F.K., Schaldemose, H., Atkinson, L., 
Wichmann, M. and Perez-Cueto, A. (2016) Increasing Fruit and Vegetable Intake among Male University Students in an Ad Libitum Buffet Setting: A Choice Architectural Nudge Intervention. Food Quality and Preference, 49, 183-188.

https:/doi.org/10.1016/j.foodqual.2015.12.006

[5] Prochaska, J.O. and DiClemente, C.C. (1986) Toward a Comprehensive Model of Change. In: Miller, W.R. and Heather, N., Eds., Treating Addictive Behaviors. Processes of Change, Plenum Press, New York, 3-27. https:/doi.org/10.1007/978-1-4613-2191-0 1

[6] Wiedemann, A.U., Lippke, S., Reuter, T., Schüz, B., Ziegelmann, J.P. and Schwarzer, R. (2009) Prediction of Stage Transitions in Fruit and Vegetable Intake. Health Education Research, 24, 596-607. https:/doi.org/10.1093/her/cyn061

[7] Richert, J., Reuter, T., Wiedemann, A.U., Lippke, S., Ziegelmann, J. and Schwarzer, R. (2010) Differential Effects of Planning and Self-Efficacy on Fruit and Vegetable Consumption. Appetite, 54, 611-614. https:/doi.org/10.1016/j.appet.2010.03.006

[8] Lhakhang, P., Godinho, C., Knoll, N. and Schwarzer, R. (2014) A Brief Intervention Increases Fruit and Vegetable Intake. A Comparison of Two Intervention Sequences. Appetite, 82, 103-110. https:/doi.org/10.1016/j.appet.2014.07.014

[9] Ajzen, I. (1991) The Theory of Planned Behavior. Organizational Behavior and Human Decision Processes, 50, 179-211. https:/doi.org/10.1016/0749-5978(91)90020-T

[10] Blanchard, C.M., Fisher, J., Sparling, P.B., Shanks, T.H., Nehl, E., Rhoades, R.E., et al. (2009) Understanding Adherence to 5 Servings of Fruits and Vegetables per Day: A Theory of Planned Behavior Perspective. Journal of Nutrition Education and Behavior, 41, 3-10. https:/doi.org/10.1016/j.jneb.2007.12.006

[11] Poelman, A.A.M., Delahunty, C.M. and de Graaf, C. (2001) Vegetable Preparation Practices for 5-6 Years Old Australian Children as Reported by Their Parents; Relationships with Liking and Consumption. Food Quality and Preference, 42, 20-26. https:/doi.org/10.1016/j.foodqual.2015.01.005

[12] Sherman, P.W. and Hash, G.A. (2001) Why Vegetable Recipes Are Not Very Spicy. Evolution and Human Behavior, 22, 147-163. https:/doi.org/10.1016/S1090-5138(00)00068-4

[13] Pang, B., Zhou, Q., Zhao, T.Y., He, L., Guo, J., Chen, H., et al. (2015) Innovative Thoughts on Treating Diabetes from the Perspective of Traditional Chinese Medicine. EvidenceBased Complementary and Alternative Medicine, 2015, Article ID: 905432. https:/doi.org/10.1155/2015/905432

[14] Rouhi-Boroujeni, H., Rouhi-Boroujeni, H., Heidarian, E., Mohammadizadeh, F. and Rafieian-Kopaei, M. (2015) Herbs with Anti-Lipid Effects and Their Interactions with Statins as a Chemical Anti-Hyperlipidemia Group Drugs: A Systematic Review. ARYA Atherosclerosis, 11, 244-251.

[15] Hügel, H.M. (2015) Brain Food for Alzheimer-Free Ageing: Focus on Herbal Medicines. Advances in Experimental Medicine and Biology, 863, 95-116. https:/doi.org/10.1007/978-3-319-18365-7 5

[16] Peters, J.C., Polsky, S., Stark, R., Zhaoxing, P. and Hill, J.O. (2014) The Influence of Herbs and Spices on Overall Liking of Reduced Fat Food. Appetite, 79, 183-188. https:/doi.org/10.1016/j.appet.2014.04.019

[17] Ghawi, S.K., Rowland, I. and Methven, L. (2014) Enhancing Consumer Liking of Low Salt Tomato Soup over Repeated Exposure by Herb and Spice Seasonings. Appetite, 81, 20-29. https:/doi.org/10.1016/j.appet.2014.05.029

[18] Gunn, C.A., Weber, J.L. and Kruger, M.C. (2013) Midlife Women, Bone Health, Vegetables, Herbs and Fruit Study. The Scarborough Fair Study Protocol. BMC Public Health, 13, 23. 
https:/doi.org/10.1186/1471-2458-13-23

[19] Krueger R.A. and Casey, M.A. (2009) Focus Groups: A Practical Guide for Applied Research. 4th Edition, Sage Publications, Thousand Oaks.

[20] Mayring, P. (2000) Qualitative Content Analysis, Forum: Qualitative Social Research, 1, Article Number: 20.

http://www.qualitative-research.net/index.php/fqs/article/view/1089/2385

[21] Lincoln, Y.S. and Guba, E.G. (1985) Naturalistic Inquiry. Sage, Thousand Oaks.

[22] Brodsky, A. (2008) Negative Case Analysis. In: Given, L.M., Ed., The Sage Encyclopedia of Qualitative Research Methods, Sage Publications, Thousand Oaks, Vol. 2.

[23] Strauss, A.L. and Corbin, J.M. (1990) Basics of Qualitative Research: Grounded Theory Procedures and Techniques. Sage Publications, Newbury Park.

[24] Pollard, J., Kirk, S.F. and Cade, J.E. (2002) Factors Affecting Food Choice in Relation to Fruit and Vegetable Intake: A Review. Nutrition Research and Review, 15, 373-387.

https:/doi.org/10.1079/NRR200244

[25] Dijkstra, S.C., Neter, J.E., van Stralen, M.M., Knol, D.L., Brouwer, I.A., Huisman, M., et al. (2015) The Role of Perceived Barriers in Explaining Socio-Economic Status Differences in Adherence to the Fruit, Vegetable and Fish Guidelines in Older Adults: A Mediation Study. Public Health Nutrition, 18, 797-808. https:/doi.org/10.1017/S1368980014001487

[26] Cavallo, D.N., Horino, M. and McCarthy, W.J. (2016) Adult Intake of Minimally Processed Fruits and Vegetables: Associations with Cardiometabolic Disease Risk Factors. Journal of the Academy of Nutrition and Dietetics, 116, 1387-1394. https:/doi.org/10.1016/j.jand.2016.03.019

[27] Seguin, R.A., Aggarwal, A., Vermeylen, F. and Drewnowski, A. (2016) Consumption Frequency of Foods Away from Home Linked with Higher Body Mass Index and Lower Fruit and Vegetable Intake among Adults: A Cross-Sectional Study. Journal of Environmental and Public Health, 2016, Article ID: 3074241. https:/doi.org/10.1155/2016/3074241

[28] Borgi, L., Rimm, E.B., Willett, W.C. and Forman, J.P. (2016) Potato Intake and Incidence of Hypertension: Results from Three Prospective US Cohort Studies. British Medical Journal, 353, i2351. https:/doi.org/10.1136/bmj.i2351

[29] Economic Research Service (2016) 2016 Vegetables and Pulses Yearbook. http://www.ers.usda.gov/webdocs/DataFiles/Vegetable and Pulses Yearbook Tables 180 35//37715 YRBK2016 Section\%201_General.pdf

[30] Holmes, T.S. and Gate, G.E. (2008) Influences on Fruit, Vegetable, and Grain Intake of Older Men. Journal of Nutrition for the Elderly, 22, 43-61. https:/doi.org/10.1300/J052v22n03 04

[31] Lucan, S.C., Barg, F.K. and Long, J.A. (2010) Promoters and Barriers to Fruit, Vegetable, and Fast-Food Consumption among Urban, Low-Income African Americans-A Qualitative Approach. American Journal of Public Health, 100, 631-635. https:/doi.org/10.2105/AJPH.2009.172692

[32] Zeinstra, G.G., Koelen, M.A., Kok, F.J. and de Graaf, C. (2010) The Influence of Preparation Method on Children's Liking for Vegetables. Food Quality and Preference, 21, 906914. https:/doi.org/10.1016/j.foodqual.2009.12.006

[33] Yeh, M.C., Ickes, S.B., Lowenstein, L.M., Shuval, K., Ammerman, A.S., Farris, R. and Katz, D.L. (2008) Understanding Barriers and Facilitators of Fruit and Vegetable Consumption among a Diverse Multi-Ethnic Population in the USA. Health Promotion International, 23, 42-51. https:/doi.org/10.1093/heapro/dam044

[34] Sorensen, G., Stoddard, A., Peterson, K., Cohen, N., Stein, E., Palombo, R., et al. (1999) In- 
creasing Fruit and Vegetable Consumption through Worksites and Families in the Treatwell 5-A-Day Study. American Journal of Public Health, 89, 54-70.

https:/doi.org/10.2105/AJPH.89.1.54

[35] Robinson, E., Blissett, J. and Higgs, S. (2011) Recall of Vegetable Eating affects Future Predicted Enjoyment and Choice of Vegetables in British University Undergraduate Students. Journal of the American Dietetic Association, 111, 1543-1548.

https:/doi.org/10.1016/j.jada.2011.07.012

[36] Fleischhacker, S., Cason, K. and Achterberg, C. (2007) Always a Vegetable at Dinner: A Fruit and Vegetable Qualitative Study with Primary Care Providers of Preschoolers Enrolled in an Inner-City, Head Start Childcare Center. Journal of Hunger and Environmental Nutrition, 1, 55-68. https:/doi.org/10.1300/J477v01n04 05

[37] Centers for Disease Control and Prevention, US Department of Health and Human Services (2011) Strategies to Prevent Obesity and Other Chronic Diseases: The CDC Guide to Strategies to Increase the Consumption of Fruits and Vegetables.

http://www.cdc.gov/obesity/downloads/fandv 2011 web tag508.pdf

[38] Conk, S.J. and Porter, C.M. (2016) Food Gardeners' Productivity in Laramie, Wyoming: More than a Hobby. American Journal of Public Health, 106, 854-856.

https:/doi.org/10.2105/AJPH.2016.303108

[39] Rolls, B.J., Roe, L.S. and Meengs, J.S. (2010) Portion Size Can Be Used Strategically to Increase Vegetable Consumption in Adults. American Journal of Clinical Nutrition, 91, 913922. https:/doi.org/10.3945/ajcn.2009.28801

[40] Meengs, J.S., Roe, L.S. and Rolls, B.J. (2012) Vegetable Variety: An Effective Strategy to Increase Vegetable Intake in Adults. Journal of the Academy of Nutrition and Dietetics, 112, 1211-1215. https:/doi.org/10.1016/j.jand.2012.05.013

[41] Smith-Drelich, N. (2016) Buying Health: Assessing the Impact of a Consumer-Side Vegetable Subsidy on Purchasing, Consumption and Waste. Public Health Nutrition, 19, 520-529. https:/doi.org/10.1017/S1368980015001469

Submit or recommend next manuscript to SCIRP and we will provide best service for you:

Accepting pre-submission inquiries through Email, Facebook, LinkedIn, Twitter, etc.

A wide selection of journals (inclusive of 9 subjects, more than 200 journals)

Providing 24-hour high-quality service

User-friendly online submission system

Fair and swift peer-review system

Efficient typesetting and proofreading procedure

Display of the result of downloads and visits, as well as the number of cited articles

Maximum dissemination of your research work

Submit your manuscript at: http://papersubmission.scirp.org/

Or contact health@scirp.org 